\title{
Technical note: Accelerometer-based recording of heavy breathing in lactating and dry cows as an automated measure of heat load
}

\author{
Doron Bar, ${ }^{1 *}$ Moshe Kaim, ${ }^{2}$ Israel Flamenbaum, ${ }^{3}$ Boaz Hanochi, ${ }^{1}$ and Rachel L. Toaff-Rosenstein ${ }^{1}$ \\ ${ }^{1}$ SCR Engineers Ltd., POB 13564, 18 Hamelacha St., Netanya, 4250553, Israel \\ ${ }^{2}$ Agricultural Research Organization, Institute of Animal Science, Beit Dagan, 5020000, Israel \\ ${ }^{3}$ Cow Cooling Solutions Ltd., Tel Aviv, 6971836, Israel
}

\section{ABSTRACT}

Monitoring thermal status using a reliable, practical method is essential for proper cattle management during periods of high heat load. Our objective was to determine whether accelerometer-based tags, which measure heavy breathing and other behaviors on a minute-by-minute basis, accurately reflect thermal status. We hypothesized that the tags would mirror core body temperature as recorded by continuous intravaginal loggers, and that response to a cooling intervention would also be captured. Data were collected during a 3-d period from 10 late dry and 20 high-producing cows at peak lactation, each fitted with an intravaginal temperature logger and tag attached to a collar. The relationship between vaginal temperature and proportion of cows recorded as breathing heavily averaged over the three 24-h periods was described separately for each group, and during a 1-h block capturing 2 intensive cooling sessions in lactating cows. Finally, the log of the odds of a cow breathing heavily in each minute relative to vaginal temperature in cows before cooling was analyzed using a linear mixed model. The proportion of cows breathing heavily in a group mirrors changes in vaginal temperature in both dry and lactating cows. In contrast to the dry cows, lactating cows suffered from excessive heat load to a much greater degree. Cooling intensively with showers and fans effectively mitigates the effects of excessive heat load, as reflected by response in vaginal temperature and proportion of cows breathing heavily. The probability of heavy breathing increases by approximately $10 \%$ for each $0.5^{\circ} \mathrm{C}$ rise in vaginal temperature above $39.0^{\circ} \mathrm{C}$. In conclusion, accelerometer-based technology that automatically records heavy breathing provides a practical means of continuously assessing heat load status of dairy cows, whether lactating or dry, and their response to cooling intervention. This has the potential to optimize both

Received June 10, 2018.

Accepted November 8, 2018.

*Corresponding author: doronb@scrdairy.com cow and resource management during periods of high heat load.

Key words: cooling, heat stress, panting, precision farming

\section{Technical Note}

Heat load expresses the combined effect of intrinsic (within-animal) and extrinsic (environmental) factors on an organism's thermal status (Gaughan et al., 2002). Excessive heat load, which occurs when accumulated heat cannot be sufficiently dissipated (Brown-Brandl et al., 2005), causes the core body temperature $\left(38.84^{\circ} \mathrm{C}\right.$ in lactating cows with a mean daily variation from high to low of $1.25^{\circ} \mathrm{C}$ including a circadian and ultradian rhythm; Bitman et al., 1984) to increase beyond the normal range (Gaughan et al., 2008). Excessive heat load is a severe and increasing concern in both dairy and beef cattle, negatively affecting production and welfare (Karimi et al., 2015; Garner et al., 2017; Polsky and von Keyserlingk, 2017).

When ambient temperatures rise, nonevaporative means of cooling (radiation, conduction, convection) become less effective, necessitating increased reliance on evaporative mechanisms, including sweating and panting (Kibler and Brody, 1950; Berman et al., 1985). Indeed, panting is one of the primary cooling mechanisms in cattle (Gaughan and Mader, 2014). Panting includes a variety of observable changes, including tachypnea, increased thoracic and flank extensions, drooling, and extended head and neck, which can be quantified on a numerical scale (Mader et al., 2006; Gaughan et al., 2010; Tresoldi et al., 2016). Panting is initiated when peripheral thermoreceptors are stimulated, even before hypothalamic receptors sense increased core temperature (Bligh, 1959; Findlay and Ingram, 1961). Panting should therefore be a sensitive early indicator of excessive heat load (Gaughan et al., 2002; Brown-Brandl et al., 2006). For example, panting increases as both ambient and abdominally measured body temperature rise (Brown-Brandl et al., 2006; Gaughan and Mader, 2014). 
Determining thermal status using a reliable, practical, noninvasive method facilitates optimal cattle management during high heat load. Although perhaps the most accessible, measuring environmental conditions alone is insufficient, as animal-specific effects (including production level, behavior, breed, body condition, coat color, reproductive status) play a key role in determining how well the animal can cope (Silanikove et al., 2000; Brown-Brandl et al., 2006; Polsky and von Keyserlingk, 2017). For example, lactating animals are less heat tolerant versus dry cows, as lactation increases metabolic heat production (Purwanto et al., 1990). Therefore, animal-based measures reflecting both environmental and intrinsic factors are essential in determining how well an individual can cope with heat load. Respiratory rate (e.g., Tresoldi et al., 2016), body temperature (collected continuously with vaginal, abdominal, and intraruminal loggers; Gaughan and Mader, 2014), and panting scores (e.g., using an 8-level scale; Mader et al., 2006 and Gaughan et al., 2008) are used in research for this purpose.

Unfortunately, many of the above-described measures are invasive or impractical for commercial use. Intravaginal temperature loggers, as described in Burdick et al. (2011), can be used in a subset of animals to evaluate cooling efficacy on commercial dairies. However, monitoring only sentinel animals may be problematic if they are not representative of the entire population, given individual variation (Brown-Brandl et al., 2006; Gaughan et al., 2010). In general, core body temperature is challenging to obtain continuously over extended periods (Mader et al., 2002; Davis et al., 2003), and most devices lack telemetry capability, requiring removal to download the data, and thus cannot provide real-time data to inform management decisions. Recording respiratory rate is time consuming and must be done every $30 \mathrm{~min}$ to provide an accurate reflection of response to changing heat load (Tresoldi et al., 2016). Indwelling reticulo-rumen temperature boluses may be a practical solution, but dynamics in feed and water intake have local effects such that temperature measured at this location may not accurately reflect organismal heat-load level (Bewley et al., 2008; Ammer et al., 2016). Finally, panting score is a robust method for monitoring the heat-load status of individuals or groups (Mader et al., 2006) and in both Bos indicus and Bos taurus cattle (Gaughan et al., 2010), but like the other measures, is impractical for commercial use unless recording is automated.

A commercially available, accelerometer-based tag (HR-LDn tags, SCR Engineers, Netanya, Israel) has the capacity to classify every minute of the day into a single state, including eating, grazing, rumination, high activity, medium activity, resting, and heavy breathing.
Heavy breathing is reported when cows experiencing excessive heat load perform characteristic movements (e.g., forward-backward heaving, accelerated respiratory rate, increased thoracic wall extension) and the tag recognizes the magnitude, rhythm, and direction in space of this energy according to a proprietary algorithm, reflecting duration and pattern relative to other types of movements. Importantly, this tag was not validated to recognize panting according to a strict, numerical scale definition.

Our objective was to determine whether accelerometer-based neck tags accurately reflect heat load status of high-producing lactating and dry cows. We hypothesized that heavy breathing, as reported on a minute-by-minute basis by the tags, would accurately reflect heat-load status as recorded by continuous intravaginal temperature loggers (as a reliable measure of core body temperature, including diurnal changes; Vickers et al., 2010), and that response to a cooling intervention (showers and fans) would also be captured by these tags. Indeed, environmental management, including cooling mechanisms such as fans, sprinklers, and waterbeds (Fournel et al., 2017) can be used to mitigate the effects of excessive heat load. However, a significant amount of potable water is used in cow cooling (Chen et al., 2015), and the ability to cool only specific at-risk groups of cows on targeted days and times could save resources. Therefore, a practical, accurate method for assessing real-time heat load status of cattle in commercial settings is needed, informing heat abatement management decisions (Polsky and von Keyserlingk, 2017).

Data were collected from a commercial dairy farm milking approximately 300 Holsteins in the Jordan valley, Israel, between September 14 and 18, 2017. The rolling herd average is close to $12,000 \mathrm{~kg} /$ cow per yr on a 305-d basis. Cows are housed in completely roofed, compost-bedded lots, with approximately $18 \mathrm{~m}^{2}$ of lying area per animal. Dry cows are fed fresh TMR $1 \times / d$ $(0600 \mathrm{~h})$, with feed pushed up $2 \times /$ d. Lactating cows are milked $3 \times / \mathrm{d}$ and fed fresh TMR $2 \times / \mathrm{d}$ (0400 and $1200 \mathrm{~h}$ ), with feed pushed up $4 \times / \mathrm{d}$.

Two groups were concurrently enrolled in the study: 10 late dry cows (mean $250 \mathrm{~d}$ pregnant), randomly sampled from a group of 20, and 20 high-producing cows, randomly sampled from a group of 80, at peak lactation (mean 60 DIM). Experimental animals were randomly selected for inclusion from their respective cohorts and continued to be housed and managed with the rest of their group.

Dry cows were voluntarily cooled beginning at 0600 $\mathrm{h}$ within their pen for $3 \mathrm{~h}$. The cooling was performed in cycles as follows: $30 \mathrm{~s}$ of water application followed by $4.5 \mathrm{~min}$ of fan activation. Forced ventilation of ap- 
proximately $3 \mathrm{~m} / \mathrm{s}$ of air at cow level (at standing cow wither height, based on manufacturer specifications, as actual on-site field measures were not performed in the context of this trial) was produced along the feedbunk stanchions by fans spaced $5 \mathrm{~m}$ apart and $3 \mathrm{~m}$ high. The sprinklers sprayed approximately $12 \mathrm{~L} / \mathrm{min}$, spaced 1.5 $\mathrm{m}$ apart along the feed bunk stanchions from $1 \mathrm{~m}$ above the cows' backs. We estimated the proportion of cows and the actual time that they were cooled according to their tag-reported feeding time during this period. The assumption is that cows received cooling at all times that they were feeding, and conversely, while they were away from the feedbunk, were not cooled. The actual cooling time for the focal cows was $85 \pm 8$ min.

At $1400 \mathrm{~h}$ dry cows were also walked to a designated shower yard located $200 \mathrm{~m}$ from their home pen and intensively cooled for $1 \mathrm{~h}$ (cycles of $30 \mathrm{~s}$ of low-pressure spray delivering approximately $16 \mathrm{~L} / \mathrm{min}$, until cows were soaked to their skin, followed by $4.5 \mathrm{~min}$ of fan activation delivering approximately 3 to $4 \mathrm{~m} / \mathrm{s}$ of air to partially dry them). Lactating cows were walked to the shower yard before each milking (at 0230, 1030, and $1800 \mathrm{~h}$ ) and between milking (at 0800, 1330, and 2230 $\mathrm{h}$ ) for a cooling session that lasted $1 \mathrm{~h}$ between milking and $1.5 \mathrm{~h}$ before milking session.

During data collection, maximum ambient temperature was between 35 and $37^{\circ} \mathrm{C}$ and minimum was between 23 and $25^{\circ} \mathrm{C}$. The temperature-humidity index reached a maximum of 84 (range 83-85) at approximately $1400 \mathrm{~h}$ and declined to a minimum of 74 (range 73-74) during the early morning hours $(0500 \mathrm{~h})$, according to a thermometer-hydrometer station (model \#P4581, Comet System S.R.O., Bezrucova, Czech Republic) located within the lactating cow pen.

Heavy breathing was automatically recorded by accelerometer-based tags attached to collars (HR-LDn tags, SCR Engineers). The tag algorithm was trained to recognize these features after thousands of minutes of observations of cows experiencing excessive heat load. This training set came from previously collected data gathered during product development. Although the HR-LDn tags have been demonstrated as accurately classifying ruminating, resting, and grazing behaviors in pastured cows (Molfino et al., 2017), they have not yet been externally validated in the context of heavy breathing.

Experimental cows were fitted with intravaginal temperature loggers (model \#SL52T-A, Signatrol Ltd., Gloucestershire, UK) as in Burdick et al. (2011) for a $90-\mathrm{h}$ period. Temperature was logged every $2 \mathrm{~min}$ with a resolution of $0.07^{\circ} \mathrm{C}$ and accuracy of $0.15^{\circ} \mathrm{C}$. The loggers were individually calibrated and tested for accuracy by the manufacturer before our study, according to our specifications, and within the range of expected body temperature $\left(38-42^{\circ} \mathrm{C}\right)$ under our study conditions.

For the descriptive analysis, intended to express the relationship between vaginal temperature and heavy breathing probability, we averaged the data from each minute for all cows within each treatment group over the entire three 24 -h periods.

To avoid potentially confounding the basic relationship between heavy breathing and body temperature with changes resulting from the cooling intervention (showers and fans), we modeled only data from the time that the cows (both dry and lactating) were not actively cooled and excluding the $30 \mathrm{~min}$ after cooling because the vaginal temperature continued to drop during this time. For this analysis we had 106,668 min of data (14,689 min that cows were with vaginal temperature in the range of $38.0-38.49,36,092 \mathrm{~min}$ in the range of $38.5-38.99,30,483$ in the range of 39.0-39.49, 18,225 in the range of $39.5-39.99,5,729$ in the range of $40.0-40.49,1,450$ in the range of 40.5-41).

The relationship between vaginal temperature and the binary outcome heavy breathing (yes/no in a given minute) was analyzed using a linear mixed model, as we had many observations from each cow, in the following form:

$$
\begin{gathered}
\mathrm{Y}=\text { vaginal temperature }+ \text { vaginal temperature }{ }^{2} \\
+ \text { cow }(\text { random })+e
\end{gathered}
$$

where $\mathrm{Y}$ is the log of the odds of a cow breathing heavily in a given minute, the fixed independent variable is vaginal temperature (modeled as first and second order), the random effect (intercept) is the cow, and $e$ is the residual error.

The farm followed a precise cooling schedule and the weather was stable over the study period. Therefore, the data were averaged over the 3 study days to simplify representation. Two cows (one from each group) lost their vaginal temperature logger, such that data were analyzed from 19 lactating (106,000 min of data) and 9 dry cows $(50,000$ min of data).

The average vaginal temperature and proportion of dry cows breathing heavily varied throughout the day (Figure 1). The morning cooling session dramatically decreased vaginal temperature, causing it to drop from approximately $39.0^{\circ} \mathrm{C}$ before cooling, with almost no heavy breathing observed, to $38.6^{\circ} \mathrm{C}$ afterward. In contrast, before the noon cooling session, vaginal temperatures reached approximately $39.4^{\circ} \mathrm{C}$, and concurrently, $12 \%$ of the group was recorded as breathing heavily.

Several times during the day, the vaginal temperature of lactating cows exceeded the normal range. Simultaneously, the proportion of cows breathing heavily 


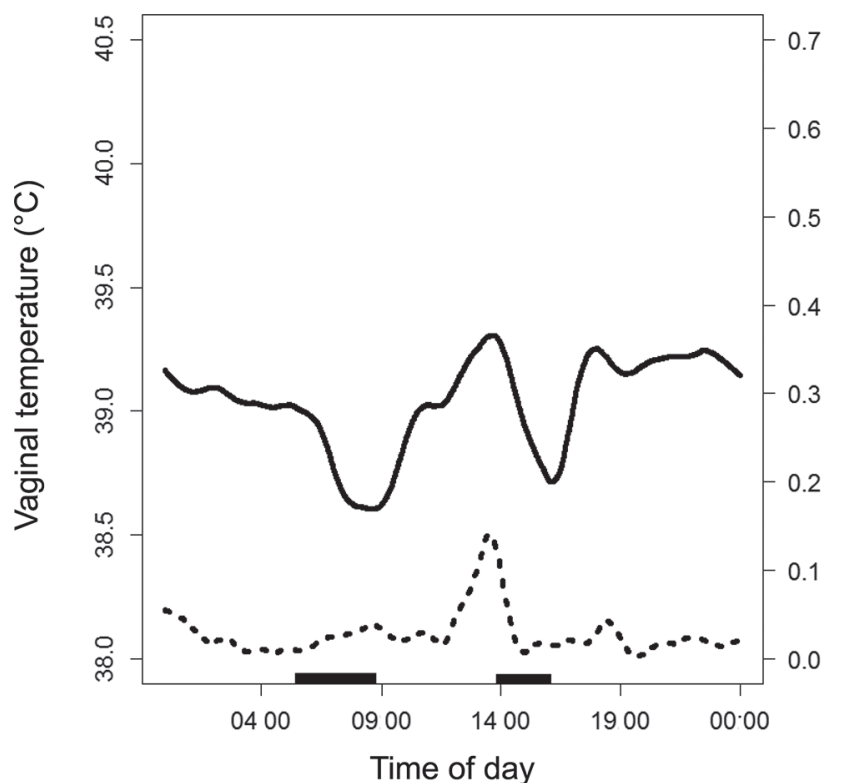

Figure 1. Mean vaginal temperature (averaged for three 24-h periods in degrees Celsius; solid line) and percentage of cows recorded as breathing heavily (dashed line) on a minute-by-minute basis for the 9 dry cows. Cooling times are indicated by thick lines on the x-axis.

mirrored the changes in core body temperature, peaking at $\geq 50 \%$ on 2 occasions (Figure 2). Furthermore, heavy breathing preceded vaginal temperature changes, both when increasing and especially when decreasing (following cooling intervention).

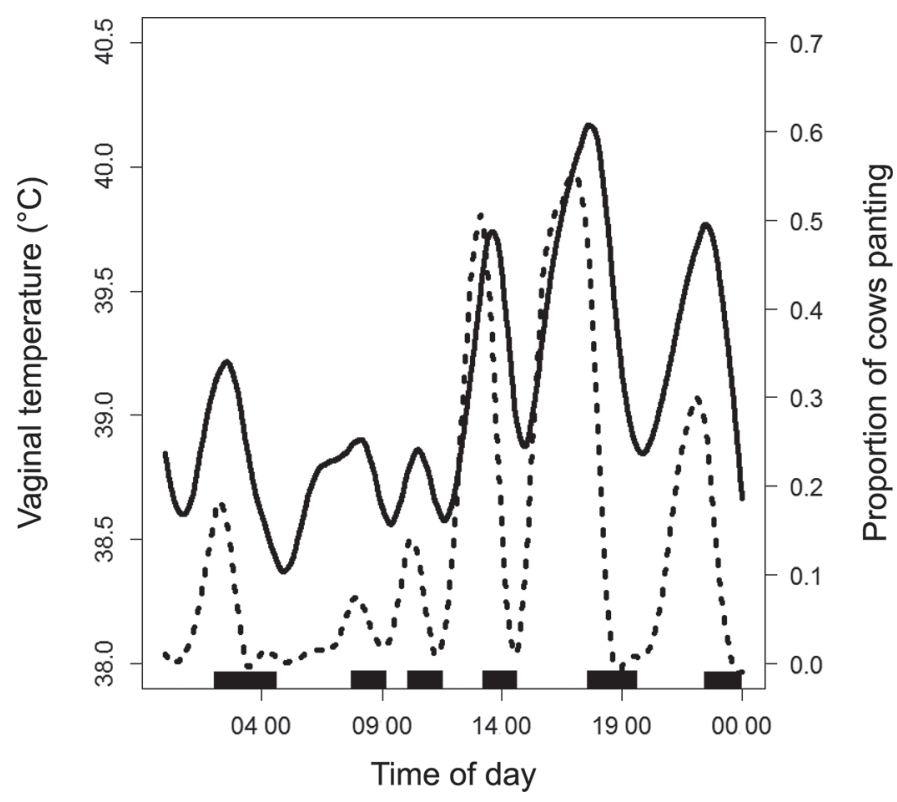

Figure 2. Mean vaginal temperature (averaged for three 24-h periods in degrees Celsius; solid line) and percentage of cows recorded as breathing heavily (dashed line) on a minute-by-minute basis for the 19 lactating cows. Cooling times are indicated by thick lines on the $\mathrm{x}$-axis.

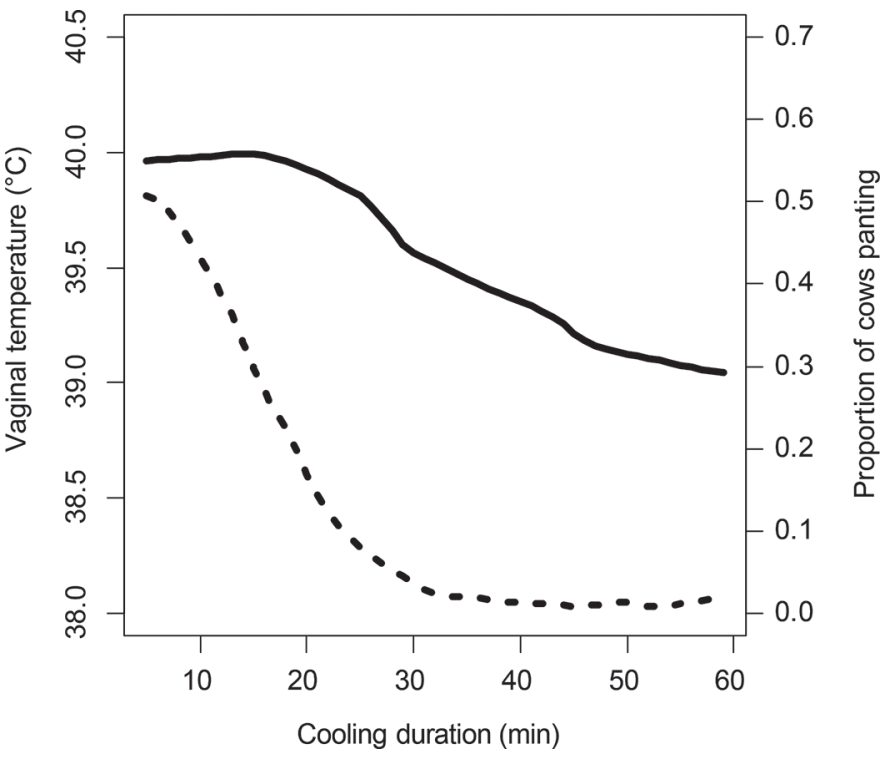

Figure 3. Mean (averaged over three 24-h periods) vaginal temperature (in degrees Celsius; solid line) and percentage of cows recorded as breathing heavily (dashed line) at the first hour of 2 cooling sessions $(1330$ and $1800 \mathrm{~h}$ ) for the 19 lactating cows.

To highlight the effect of intensive cooling on cows experiencing severe heat load, we more closely examined lactating cows at 2 daytime cooling sessions (1330 and $1800 \mathrm{~h}$; Figure 3). As soon as cooling began, the percentage of cows breathing heavily declined, reaching close to 0 after $30 \mathrm{~min}$. Vaginal temperature had a time lag of about 15 min and was still declining after $1 \mathrm{~h}$ of cooling.

The tag reports on a minute-by-minute basis based on continuous activity sampling and according to the predominant features of the animal's behavior, contained within a proprietary algorithm. A descriptive example to characterize the tag's reporting relative to simultaneously measured vaginal temperature is provided from a lactating cow over a 4 -h period (Figure 4). As vaginal temperature increased, the tag primarily reported heavy breathing, while during and after cooling, rumination, then eating were the predominant states reported.

The predicted probability of heavy breathing in both dry and lactating cows in any given minute relative to vaginal temperature level along with $95 \%$ confidence interval was calculated according to a statistical model (Figure 5). Probability of heavy breathing increases by approximately $10 \%$ for each $0.5^{\circ} \mathrm{C}$ rise in vaginal temperature between 39.0 and $40.5^{\circ} \mathrm{C}$. Above $40.6^{\circ} \mathrm{C}$, panting probability seems to decline. It appears that once heavy breathing probability reaches or exceeds $10 \%$, core body temperature has reached or surpassed upper critical limits. 


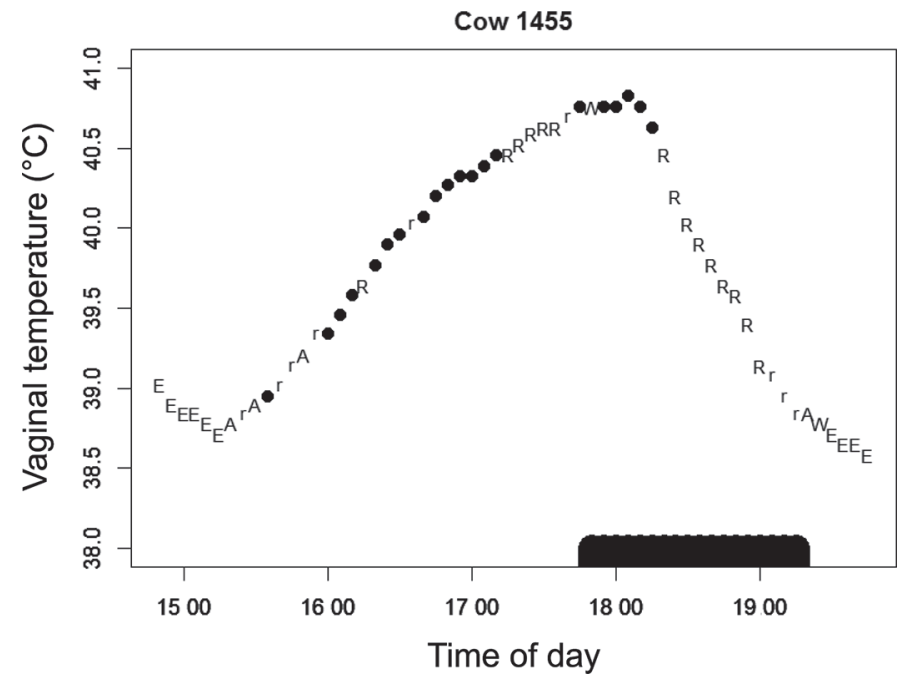

Figure 4. Vaginal temperature of a single lactating cow over $4 \mathrm{~h}$ along with tag-reported activity at that time (filled circle $=$ breathing heavily, $\mathrm{R}=$ rumination, $\mathrm{E}=$ eating, $\mathrm{A}=$ active, $\mathrm{r}=$ rest, $\mathrm{W}=$ walking). Time of cooling session is indicated by a thick line on the $\mathrm{x}$-axis.

There is a critical need for technology that enables continuous, noninvasive monitoring for excessive heat load and optimal implementation of cooling strategies. To this end, our primary objective was to determine whether a device that continuously tracks cattle behavior, including heavy breathing, can replace vaginal temperature loggers, which are impractical in commercial settings. Accelerometer-based neck tags accurately reflect response to heat load, including differences between cows of varying metabolic status (dry and peak lactation). The proportion of animals breathing heavily in any given minute is closely related to vaginally mea-

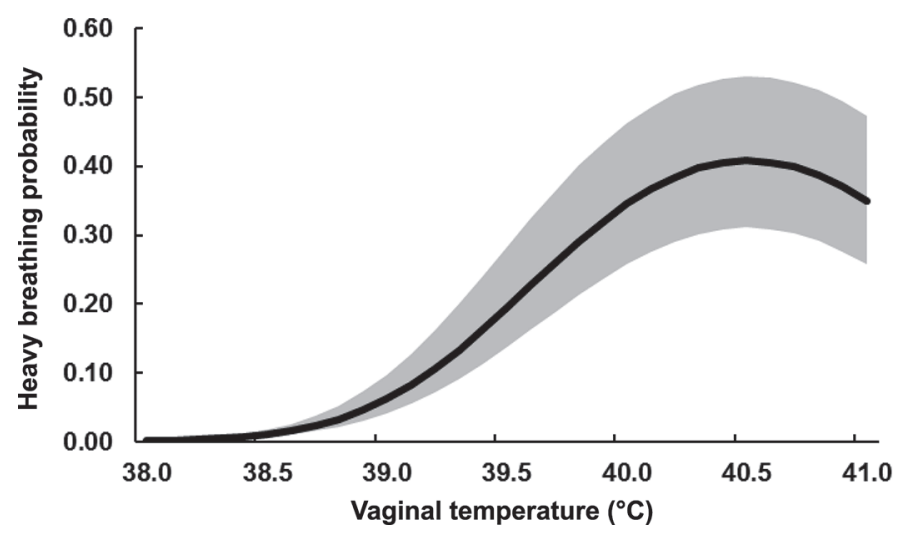

Figure 5. Predicted probability that heavy breathing will be reported in cows (both dry and lactating) in any given minute relative to vaginal temperature, including $95 \%$ CI. Results are from a generalized mixed model that contained first- and second-order vaginal temperature as fixed effect and cow as random effect (28 cows over $3 \mathrm{~d}$ outside of cooling sessions and $30 \mathrm{~min}$ after cooling, about 107,000 $\mathrm{min}$ ). sured core temperature. Namely, as core temperature increases, the proportion of cows breathing heavily is higher. As expected, dry cows, with their much lower metabolic heat load, have considerably less heavy breathing compared with those at peak lactation.

A secondary objective was to determine the capacity of the tags to capture the effect of intensive shower cooling, highlighting the potential to implement this heat abatement strategy based on real-time monitoring. Increased heavy breathing before the start of cooling indicates a need for timely intervention, while the rapid decrease during and following use of showers and fans indicates lowered heat load in response. Taken together, these results highlight the capacity of accelerometer-based tags that report heavy breathing on a minute-by-minute basis to optimize both cow and resource management during high heat load.

An approximately 15-min gap was observed between changing vaginal temperatures and proportion of cows breathing heavily, during periods of both rising ambient temperatures, and during and immediately following cooling intervention. There are 2 complementary explanations for this. First, rectal or vaginal temperature is an imperfect approximation of tympanic membrane temperature, the latter of which is most relevant when gauging hypothalamically controlled responses, including panting, to changing ambient conditions. Indeed, tympanic membrane temperature closely approximates that sensed by hypothalamic receptors, and responds more quickly, by as much as $18 \mathrm{~min}$, than rectal (and by extension, vaginal) temperature to both rising and falling ambient temperatures (Guidry and McDowell, 1966). Given this, it makes sense that centrally sensed temperature will regulate panting levels even before rectally or vaginally measured temperature reflect heat load as dictated by changing ambient conditions. Second, at body temperatures below $40^{\circ} \mathrm{C}$, respiration is controlled primarily by peripheral stimulation, and only at higher temperatures does core stimulation become the primary mechanism underlying the initiation of panting (Findlay and Ingram, 1961). It therefore follows that tag-recorded heavy breathing is initiated when peripheral receptors detect rising ambient temperatures, even before core body temperature increases, and similarly, that heavy breathing stops in showercooled cows before vaginally recorded temperatures have normalized.

Despite differences between individual cows in susceptibility to excessive heat load, cooling strategies (including showers, fans, and shade) are implemented at the pen level. For this reason, even though the HR-LDn tags monitor at the individual cow level, the relevant output for intervention purposes is the proportion of a given group that is breathing heavily. 
Importantly, this rate must be calculated in animals that have not yet been cooled, because the relationship between heavy breathing and core body temperature is altered once cooling has begun (i.e., panting decreases as peripheral receptors sense cool water, but body temperature is still elevated above normal levels).

One limitation of this technology is that heavy breathing is classified as a binary trait, unlike numerical scale panting scores assigned by human observers. Additionally, the tag continuously samples behavior, which may change frequently, and reports on a minuteby-minute basis, such that a cow that performs several behaviors in short succession (e.g., walking, resting, and heavy breathing) may not be reported as breathing heavily at that time, even if she did in fact pant for some portion of a minute. This is because the tag computes according to a variety of proprietary factors, and considering many aspects of the input signal, and not according to a strict threshold. However, because overheated cows spend a substantial portion of time panting, when monitored continuously and examined at the group level, the heat load status of the individuals within the group is captured as a function of the proportion of the group breathing heavily. Finally, it is possible that in cows experiencing very high levels of heat load, there will be an apparent decrease in tagreported heavy breathing. One possible explanation is that following prolonged panting, respiratory alkalosis may develop secondary to excessive loss of carbon dioxide (in the form of carbonic acid; Benjamin, 1981). This causes a shift in the respiratory pattern, termed the biphasic respiratory response, from rapid and shallow to slower and deeper breathing, to compensate for this pH imbalance (Gaughan and Mader, 2014). Although no direct observations were performed in the current study, this possibly explains why the probability of heavy breathing decreased at the highest vaginal body temperatures, if indeed the tag primarily captures the rapid, shallow movements associated with the first phase of the biphasic response.

In the future, it is of interest to clarify exactly what severity level of heavy breathing the HR-LDn tags capture (in other words, the threshold at which this response is reported) based on visual observations. Similarly, given the tag's capacity to classify many behaviors, it likely that a robust, multimodal warning index could be developed, based not only on heavy breathing, but also on additional changes observed in response to excessive heat load, and which the tag has the capacity to capture, including decreased and altered timing of feeding, lower activity level, and decreased rumination (West, 2003; Brown-Brandl et al., 2006; Allen et al., 2015; Garner et al., 2017).
In conclusion, accelerometer-based technology that automatically records heavy breathing provides a practical means of continuously assessing heat load status of dairy cows, whether lactating or dry, and their response to cooling intervention. This has the potential to optimize both cow and resource management during periods of high heat load.

\section{ACKNOWLEDGMENTS}

The authors thank the personnel of the study dairy for their valuable cooperation during the study. The study was funded by SCR Engineers Ltd., Netanya, Israel.

\section{REFERENCES}

Allen, J. D., L. W. Hall, R. J. Collier, and J. F. Smith. 2015. Effect of core body temperature, time of day, and climate conditions on behavioral patterns of lactating dairy cows experiencing mild to moderate heat stress. J. Dairy Sci. 98:118-127. https://doi.org/10 .3168/jds.2013-7704.

Ammer, S., C. Lambertz, and M. Gauly. 2016. Is reticular temperature a useful indicator of heat stress in dairy cattle? J. Dairy Sci. 99:10067-10076. https://doi.org/10.3168/jds.2016-11282.

Benjamin, M. M. 1981. Fluid and electrolytes. Pages 213-228 in Outline of Veterinary Clinical Pathology. Iowa State Univ. Press, Ames.

Berman, A., Y. Folman, M. Kaim, M. Mamen, Z. Herz, D. Wolfenson, A. Arieli, and Y. Graber. 1985. Upper critical temperatures and forced ventilation effects for high-yielding dairy cows in a subtropical climate. J. Dairy Sci. 68:1488-1495.

Bewley, J. M., M. E. Einstein, M. W. Grott, and M. M. Schutz. 2008. Comparison of reticular and rectal core body temperatures in lactating dairy cows. J. Dairy Sci. 91:4661-4672. https://doi.org/10 $.3168 /$ jds.2007-0835.

Bitman, J., A. Lefcourt, D. L. Wood, and B. Stroud. 1984. Circadian and ultradian temperature rhythms of lactating dairy cows. J. Dairy Sci. 67:1014-1023.

Bligh, J. 1959. The receptors concerned in the thermal stimulus to panting in sheep. J. Physiol. 146:142-151.

Brown-Brandl, T. M., R. A. Eigenberg, J. A. Nienaber, and G. L. Hahn. 2005. Dynamic response indicators of heat stress in shaded and non-shaded feedlot cattle, Part 1: Analysis of indicators. Biosyst. Eng. 90:451-462.

Brown-Brandl, T. M., J. A. Nienaber, R. A. Eigenberg, T. L. Mader, J. L. Morrow, and J. W. Dailey. 2006. Comparison of heat tolerance of feedlot cattle of different breed. Livest. Sci. 105:19-26.

Burdick, N. C., J. A. Carroll, J. W. Dailey, R. D. Randel, S. M. Falkenberg, and T. B. Schmidt. 2011. Development of a self-contained, indwelling vaginal temperature probe for use in cattle research. J. Therm. Biol. 37:339-343. https://doi.org/10.1016/j.jtherbio.2011 .10 .007 .

Chen, J. M., K. E. Schütz, and C. B. Tucker. 2015. Cooling cows efficiently with sprinklers: Physiological responses to water spray. J. Dairy Sci. 98:6925-6938. https://doi.org/10.3168/jds.2015-9434.

Davis, M. S., T. L. Mader, S. M. Holt, and A. M. Parkhurst. 2003. Strategies to reduce feedlot cattle heat stress: Effects on tympanic temperature. J. Anim. Sci. 81:649-661.

Findlay, J. D., and D. L. Ingram. 1961. Brain temperature as a factor in the control of thermal polypnoea in the ox (Bos taurus). J. Physiol. 155:72-85.

Fournel, S., V. Ouellet, and E. Charbonneau. 2017. Practices for alleviating heat stress of dairy cows in humid continental climates: A 
literature review. Animals (Basel) 7:E37. https://doi.org/10.3390/ ani7050037.

Garner, J. B., M. Douglas, S. R. O. Williams, W. J. Wales, L. C. Marett, K. DiGiacomo, B. J. Leury, and B. J. Hayes. 2017. Responses of dairy cows to short-term heat stress in controlled-climate chambers. Anim. Prod. Sci. 57:1233-1241. https://doi.org/10.1071/ AN16472.

Gaughan, J. B., and T. L. Mader. 2014. Body temperature and respiratory dynamics in un-shaded beef cattle. Int. J. Biometeorol. 58:1443-1450.

Gaughan, J. B., T. L. Mader, S. M. Holt, G. L. Hahn, and B. A. Young. 2002. Review of current assessment of cattle and microclimate during periods of high heat load. Anim. Prod. Aust. 24:77-80.

Gaughan, J. B., T. L. Mader, S. M. Holt, and A. Lisle. 2008. A new heat load index for feedlot cattle. J. Anim. Sci. 86:226-234.

Gaughan, J. B., T. L. Mader, S. M. Holt, M. L. Sullivan, and G. L. Hahn. 2010. Assessing the heat tolerance of 17 beef cattle genotypes. Int. J. Biometeorol. 54:617-627. https://doi.org/10.1007/ s00484-009-0233-4.

Guidry, A. J., and R. E. McDowell. 1966. Tympanic membrane temperature for indicating rapid changes in body temperature. J. Dairy Sci. 49:74-77.

Karimi, M. T., G. R. Ghorbani, S. Kargar, and J. K. Drackley. 2015. Late-gestation heat stress abatement on performance and behavior of Holstein dairy cows. J. Dairy Sci. 98:6865-6875. https://doi .org/10.3168/jds.2014-9281.

Kibler, H. H. and S. Brody. 1950. Environmental physiology with special reference to domestic animals. X. Influence of temperature, $5^{\circ}$ to $95^{\circ} \mathrm{F}$, on evaporative cooling from the respiratory and exterior surfaces in Jersey and Holstein cows. Missouri Agric. Exp. Sta. Res. Bull. 461. Columbia, MO.
Mader, T. L., M. S. Davis, and T. Brown-Brandl. 2006. Environmental factors influencing heat stress in feedlot cattle. J. Anim. Sci 84:712-719.

Mader, T. L., S. M. Holt, G. L. Hahn, M. S. Davis, and D. E. Spiers. 2002. Feeding strategies for managing heat load in feedlot cattle. J. Anim. Sci. 80:2373-2382.

Molfino, J., C. E. F. Clark, K. L. Kerrisk, and S. C. Garcia. 2017. Evaluation of an activity and rumination monitor in dairy cattle grazing two types of forages. Anim. Prod. Sci. 57:1557-1562.

Polsky, L., and M. A. G. von Keyserlingk. 2017. Invited review: Effects of heat stress on dairy cattle welfare. J. Dairy Sci. 100:8645-8657. https://doi.org/10.3168/jds.2017-12651.

Purwanto, B. P., Y. Abo, R. Sakamoto, F. Furumoto, and S. Yamamoto. 1990. Diurnal patterns of heat production and heart rate under thermoneutral conditions in Holstein Friesian cows differing in milk production. J. Agric. Sci. 114:139-142. https://doi.org/10 $.1017 / \mathrm{s} 0021859600072117$.

Silanikove, N. 2000. Review article: Effects of heat stress on the welfare of extensively managed domestic ruminants. Livest. Prod. Sci. 67:1-18.

Tresoldi, G., K. E. Schütz, and C. B. Tucker. 2016. Assessing heat load in drylot dairy cattle: Refining on-farm sampling methodology. J. Dairy Sci. 99:8970-8980. https://doi.org/10.3168/jds.2016-11353.

Vickers, L. A., O. Burfeind, M. A. G. von Keyserlingk, D. M. Veira, D. M. Weary, and W. Heuwieser. 2010. Technical note: Comparison of rectal and vaginal temperatures in lactating dairy cows. J. Dairy Sci. 93:5246-5251.

West, J. W. 2003. Effects of heat-stress on production in dairy cattle. J. Dairy Sci. 86:2131-2144. 